\title{
BIOFILTRATION KINETICS OF ETHYL ACETATE AND XYLENE USING SUGARCANE BAGASSE BASED BIOFILTER
}

\author{
V. Saravanan*, M. Rajasimman, N.Rajamohan \\ Department of Chemical Engineering, Annamalai University, Annamalai Nagar-608002, Tamil Nadu, India
}

Received 28 March 2010; received in revised form 21 May 2010

\begin{abstract}
Biodegradation kinetic behaviors of ethyl acetate and xylene in a sugarcane bagasse biofilter were investigated. Microbial growth rate, biochemical reaction rate and kinetic analysis were inhibited at higher inlet concentration. For the microbial growth process, the microbial growth rate of ethyl acetate was greater than that of xylene in the inlet concentration range of $0.2-1.2 \mathrm{~g} \mathrm{~m}^{-3}$. The degree of inhibitive effect was almost the same for ethyl acetate and xylene in this concentration range. The half-saturation constant $K_{s}$ values of ethyl acetate and xylene were 1.8489 and $1.784 \mathrm{~g} \mathrm{~m}^{-3}$, respectively. The maximum reaction rate $V_{m}$ values of ethyl acetate and xylene were 0.8073 and $0.8438 \mathrm{gC} \mathrm{kg}^{-1} \mathrm{~h}^{-1}$ packed material, respectively at a concentration of $0.2 \mathrm{~g} \mathrm{~m}^{-3}$. For the biochemical reaction process, the biochemical reaction rate of ethyl acetate was greater than that of xylene in the inlet concentration range of $0.2-1.2 \mathrm{~g} \mathrm{~m}^{-3}$. The inhibitive effect for ethyl acetate was more pronounced than that for $0.2-1.2 \mathrm{~g} \mathrm{~m}^{-3}$ in this concentration range. The EAX concentration profiles along the depth were also determined by using diffusion reaction model. It was observed that at low concentration and low flow rate, the model is in good agreement with the experimental values for ethyl acetate and xylene.
\end{abstract}

Keywords: Xylene, ethyl acetate, sugarcane bagasse, biofilter, biochemical reaction

DOI:10.3329/cerb.v14i1.4683

\section{Introduction}

The removal of Volatile Organic Compounds (VOCs) from a polluted air stream using a biological process is highly efficient and has low installation and operation/maintenance costs. Biofiltration technology offers environmental advantages: it does not generate undesirable byproducts by converting many organic and inorganic compounds into harmless oxidation products (e.g., water and carbon dioxide). Biofiltration involves the passage of a polluted air stream through a packed bed containing microorganisms immobilized within a biofilm attached to the bed-packing material. Contaminants are transferred to the interface between the gas and biofilm and are subsequently absorbed into the biofilm. Contaminants are then used as carbon and/or energy sources for the microorganisms within the biofilm. The solid filter material provides a nutrient source and matrix for the attachment of microorganisms in the biofiltration process. Therefore, the filter material property is an important factor in obtaining optimal pollutant removal. The optimal filter material should have the following characteristics: high moisture holding capacity, porosity, available nutrients, compression strength, and $\mathrm{pH}$ buffer capacity [1].

Carbon, nitrogen, and phosphorus are three important nutrients for microbial growth and metabolism. Carbon can be provided by the VOCs in the air stream, but both nitrogen and phosphorus must be provided by the filter material. Nitrogen is a major constituent of microorganism proteins and nucleic acids because it can make up approximately $15 \%$ of

${ }^{*}$ Corresponding author, Email:sarav304@gmail.com microbial cell dry weight [2]. Consequently, nitrogen can be a limiting nutrient if adequate amounts are not available in the biofilter material. Inorganic nitrogen (i.e., ammonia, nitrate, or nitrite) is water-soluble and can be considered as the available nitrogen for microorganisms. Inorganic nitrogen is generally not initially present in the filter material. It is formed by the mineralization of organic nitrogen in the filter material and by recycling nitrogen through the mineralization of cells.

Ethyl acetate (EA) and Xylene (X) are widely used industrial chemicals. These compounds are high-priority toxic chemicals. Large volumes of these compounds are released into the atmosphere during manufacturing processes every year, endangering the air quality and public health. Removal of ethyl acetate from waste gas by a trickle-bed air biofilter was evaluated. It was reported that the elimination capacity and the removal efficiency increased and decreased with increasing influent loading, respectively [3]. Removal of butyl acetate and xylene mixtures using a trickle-bed air biofilter was studied. It was found that almost complete VOC removal was attained with influent carbon load of butyl acetate and xylene below 40 and $45 \mathrm{~g} \mathrm{~m}^{-3} \mathrm{~h}^{-1}$, respectively. VOCs removal efficiencies were higher than $80 \%$ as the influent carbon load of butyl acetate and xylene increased up to 150 and $110 \mathrm{~g} \mathrm{~m}^{-3} \mathrm{~h}^{-1}$ [4]. The maximum elimination capacity of ethyl acetate in the compost-wood and compostpolystyrene biofilter at ethyl acetate inlet concentration of $8.4 \mathrm{~g} \mathrm{~m}^{-3}$ was 200 and $300 \mathrm{~g} \mathrm{~m}^{-3} \mathrm{~h}^{-1}$, respectively. The compost-polystyrene biofilter had greater elimination capacity because the medium had higher porosity and larger active surface [5]. A gas-liquid-solid three-phase flow airlift loop 
bioreactor was applied to treat air streams containing a mixture of ethyl acetate and ethanol. The elimination capacities of ethyl acetate $\left(504 \mathrm{~g} \mathrm{~m}^{-3} \mathrm{~h}^{-1}\right)$ or ethanol $\left(685 \mathrm{~g} \mathrm{~m}^{-3} \mathrm{~h}^{-1}\right)$ in the mixture as two mixture pollutants were greater than those of pure ethyl acetate $\left(480 \mathrm{~g} \mathrm{~m} \mathrm{~m}^{-3} \mathrm{~h}^{-1}\right)$ or ethanol $(671 \mathrm{~g} \mathrm{~m}$ $\left.\mathrm{m}^{-3} \mathrm{~h}^{-1}\right)$ as single pollutant [6]. Biofiltration of ethyl acetate, toluene and a 1:1 mixture was investigated. The maximum elimination capacity of pure ethyl acetate and toluene as single pollutant in the peat biofilter were 190 and $150 \mathrm{gC}$ $\mathrm{m}^{-3} \mathrm{~h}^{-1}$, respectively. The removal efficiency of ethyl acetate was not significantly affected by the presence of toluene, but toluene degradation was inhibited in the presence of ethyl acetate and the maximum elimination capacity of toluene decreased to $80 \mathrm{gC} \mathrm{m}^{-3} \mathrm{~h}^{-1}$ [7]. Recently, we had observed that the process for degradation of VOCs in a composite bead biofilter could be divided into lag, log growth and maximum stationary three phases, and the log growth and maximum stationary phases were important for controlling the removal efficiency of biofilter [8, 9]. Therefore, studies the kinetic of $\log$ growth and maximum stationary phases was very important for operating and design on the biofiltration. However, details of the kinetic of such biodegradation processes in biofilter are scant in the relevant literature. This article investigates the biodegradation kinetic behaviors of ethyl acetate and xylene in a sugarcane bagasse based biofilter. The relationships between the microbial growth rate, biochemical reaction rate and kinetic analysis with inlet VOCs concentration are studied.

\section{Materials and Methods}

\subsection{Medium and inoculum preparation}

The inoculum was the two month acclimatized culture seeded with activated sludge from the secondary clarifier of the pharmaceutical wastewater treatment plant. $200 \mathrm{ml}$ of the concentrated diluted with following nutrient solution, $\mathrm{KH}_{2} \mathrm{PO}_{4} ; 1.19 \mathrm{~g} \mathrm{~L}^{-1}, \mathrm{Na}_{2} \mathrm{HPO}_{4} \cdot 12 \mathrm{H}_{2} \mathrm{O} ; 3.13 \mathrm{~g} \mathrm{~L}^{-1}, \mathrm{KNO}_{3}$ ; $3.88 \mathrm{~g} \mathrm{~L}^{-1},\left(\mathrm{NH}_{4}\right)_{2} \mathrm{SO}_{4} ; 2.58 \mathrm{~g} \mathrm{~L}^{-1}, \mathrm{FeSO}_{4} ; 0.35 \mathrm{~g} \mathrm{~L}^{-1}$, $\mathrm{MgSO}_{4} \cdot 7 \mathrm{H}_{2} \mathrm{O} ; 0.35 \mathrm{~g} \mathrm{~L}^{-1}, \mathrm{NaHCO}_{3} ; 0.90 \mathrm{~g} \mathrm{~L}^{-1}, \mathrm{MnSO}_{4}$ $1.52 \mathrm{mg} \mathrm{L}^{-1}, \mathrm{Na}_{2} \mathrm{MoO}_{4} ; 1.0 \mathrm{mg} \mathrm{L}^{-1}, \mathrm{CaCl}_{2} ; 3.0 \mathrm{mg} \mathrm{L}^{-1}$ - In order to obtain a microbial population adapted to the mixed pollutants (EA and Xylene), reactor was continuously fed with EA and Xylene mixture (with different inlet concentration of EA and Xylene), respectively, at a rate of 0.03-0.12 $\mathrm{g} \mathrm{m}^{-3} \mathrm{~h}^{-1}$ for a period of 160 days. Sugarcane bagasse was obtained from MRK Sugarcane industry, Sethiatthoppu, India and it was used as filter material.

\subsubsection{Experimental set-up and monitoring of biofilters}

The organic compound removal was carried out in a laboratory-scale biofilter (Figure 1). The EAX mixture was prepared for a different concentration of $0.2,0.4,0.6$ and 1.2 $\mathrm{g} \mathrm{m}^{-3}$. The biofilter was made of methacrylate, with a total height of $100 \mathrm{~cm}$ and an internal diameter of $5 \mathrm{~cm}$. A 10 $\mathrm{cm}$ head-space was used for the waste gas inlet and for nutrient feed, while a $15 \mathrm{~cm}$ bottom space was for the treated gas outlet and leachate. The biofilter was equipped with four sampling ports to measure EAX concentrations, located at

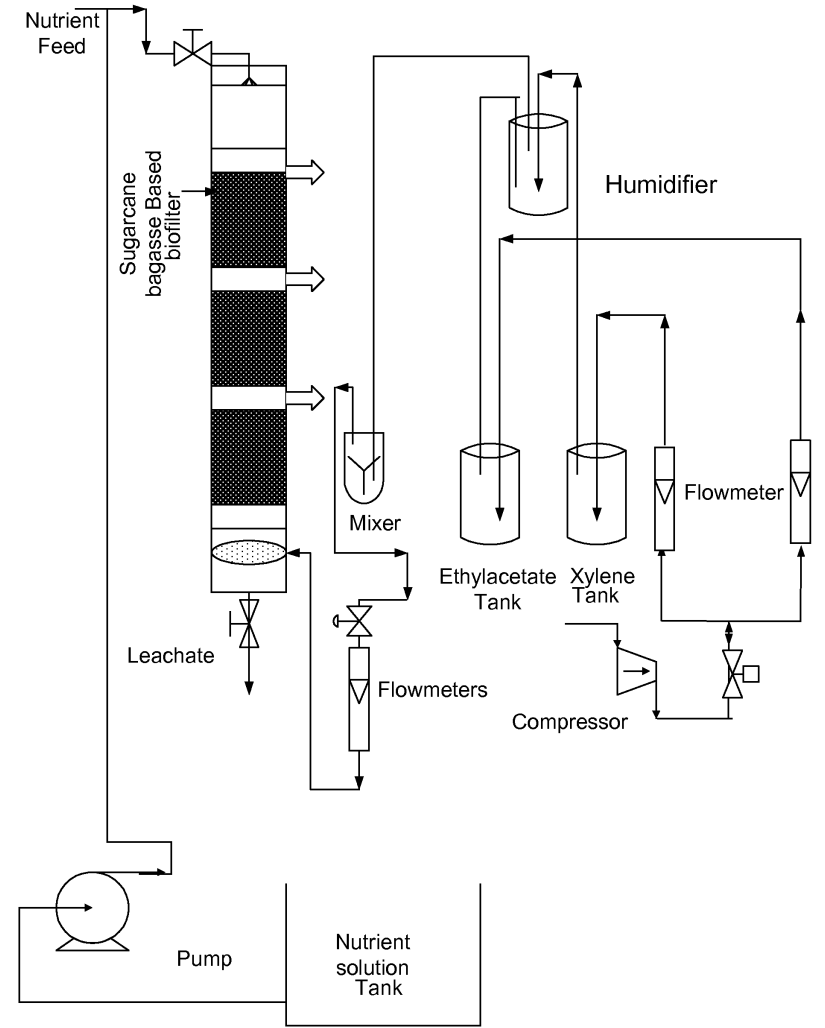

Figure 1: Schematic diagram of biofiltration unit

0 (inlet port), 25, 50 and 75, (outlet port) $\mathrm{cm}$ of the column height. Compressed, filtered and dried gas was passed through a humidifier to ensure a relative humidity value of at least $90 \%$ to avoid drying of the packing material in the biofilter bed. The EBRT was adjusted by using a rotameter (Planck, India). The required flow of pollutant was introduced in to the gas stream by using a compressor and, then, the contaminated gas was flowed upwards into the bed.

\section{Results and Discussion}

The variations of VOCs removal efficiency with operation time for two compounds are shown in Figure 2 (only the inlet concentration of $0.2 \mathrm{~g} \mathrm{~m}^{-3}$ is shown because the data for the other concentrations were visually similar). It was found that the variations of VOCs removal efficiency with operation time appeared in three phases: lag phase (phase I), log growth phase (phase II) and maximum stationary phase (phase III) $[10,11]$. Only the biochemical kinetic behaviors in the log growth and maximum stationary phases were studied in this work. The effect of inlet concentration and type of compounds on the microbial growth rate and biochemical reaction rate was investigated. The elimination capacity of two acetate compounds was also determined.

\subsection{Microbial growth process}

In the log growth phase (phase II), the microbial growth rate increased exponentially and was represented by the fol- 


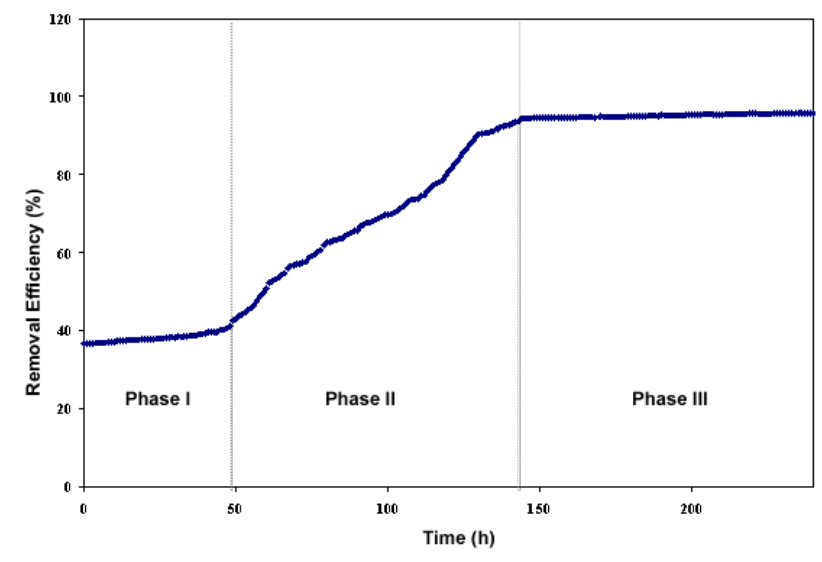

(a) ethyl acetate

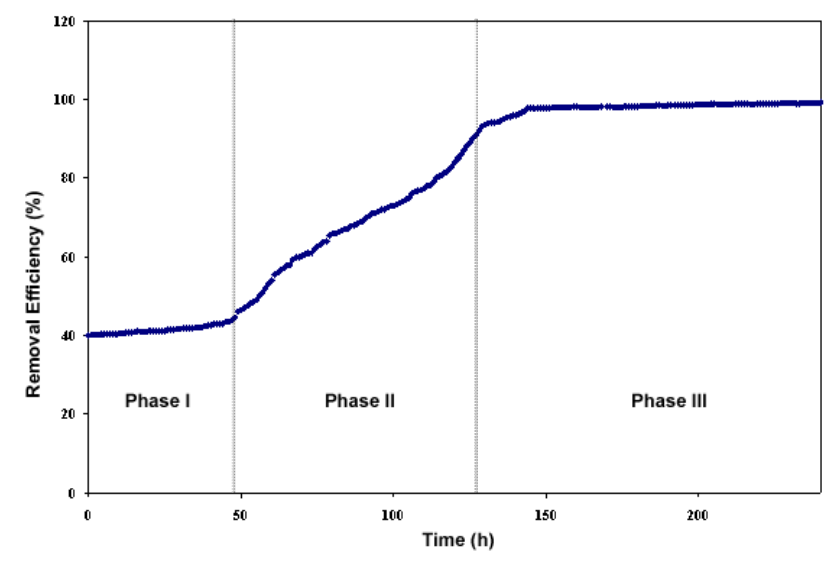

(b) xylene

Figure 2: The variations of VOCs removal efficiency with operation time $(\mathrm{t})$ for the biofilter at the inlet concentration at $0.2 \mathrm{~g} \mathrm{~m}{ }^{-3}$

lowing equation [12]:

$$
\frac{d X}{d t}=K_{g} X
$$

where $X$ is the number of viable cells per unit volume, $K_{g}$ is the microbial growth rate and $t$ is the operation time. Because contaminant degradation was the result of microbial activity, more amount of viable cell per unit volume in the bed would consume more amount of contaminant. Thus, the kinetic of contaminant degradation is closely related to the kinetics of microbial growth [12]. A cell yield coefficient $y$ is defined as the ratio of mass of cell created $(d X / d t)$ to the mass of contaminant degraded $(d C / d t)$ [13], then Equation 1 can be expressed as:

$$
\frac{d C}{d t}=K_{g} C
$$

Integration of Equation 3 yields

$$
\ln \frac{C}{C_{0}}=K_{g} t
$$

where $C_{0}$ is the concentration of VOCs in the inlet air stream. A plot of $\ln \left(C / C_{0}\right)$ versus $t$ should correspond to a straight line and $K_{g}$ can be determined. The microbial growth rate $K_{g}$ of two compounds at various inlet concentrations was calculated from the data in phase.

The variations of the $K_{g}$ values with inlet concentration $C_{0}$ for two compounds are shown in Figure 3. The $K_{g}$ value of ethyl acetate was greater than that of xylene in the inlet concentration range of $0.2-1.2 \mathrm{~g} \mathrm{~m}^{-3}$. The result indicated that the microbial growth rate of ethyl acetate was greater than that of xylene in this concentration range. The water solubility of ethyl acetate $\left(85 \mathrm{~g} \mathrm{~L}^{-1} \mathrm{H}_{2} \mathrm{O}\right)$ was greater than that of xylene $\left(0.3 \mathrm{~g} \mathrm{~L}^{-1} \mathrm{H}_{2} \mathrm{O}\right)$, so the amount of ethyl acetate dissolved in the biofilm was greater than that of xylene. This phenomenon would lead more microorganisms participating in the ethylacetate biodegradation activity. The result was closely corresponding to the result reported that the specific growth rate of methyl ethyl ketone $\left(0.14 \mathrm{~h}^{-1}\right)$ was greater

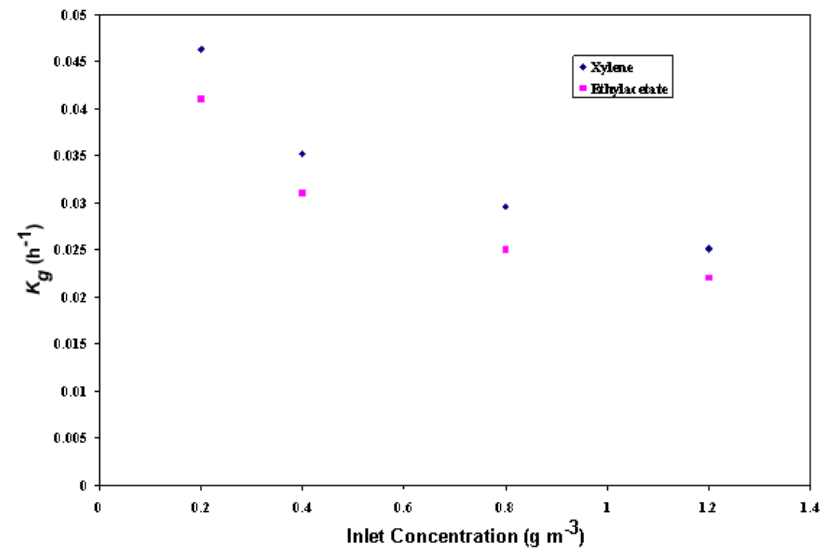

Figure 3: The variations of $K_{g}$ with inlet concentration $\left(C_{0}\right)$ for two compounds

than that of methyl butyl ketone $\left(0.12 \mathrm{~h}^{-1}\right)$ because the water solubility of methyl ethyl ketone $\left(290 \mathrm{~g} \mathrm{~L}^{-1} \mathrm{H}_{2} \mathrm{O}\right)$ was greater than that of methyl butyl ketone $\left(14 \mathrm{~g} \mathrm{~L}^{-1} \mathrm{H}_{2} \mathrm{O}\right)$ [14].

The $K_{g}$ value decreased with increasing inlet concentration in the concentration range of $0.2-1.2 \mathrm{~g} \mathrm{~m}^{-3}$ for two compounds. An increase in the inlet concentration generally would enhance the transfer rate of the VOCs from the gas phase to the biofilm. This phenomenon could explain the fact that more microorganisms were caused to participate in the biodegradation. However, high concentrations of some recalcitrant VOCs may produce inhibitive effects on the metabolic activity of the microbial population [13]. Therefore, the result indicated that the inhibitive effect predominated and the microbial growth rate was inhibited at higher inlet concentration. The result was closely corresponding to the result reported that the microbial growth rate of n-butyl acetate decreased with increasing inlet concentration [10]. The slope of the linear profiles in the concentration range of $0.2-1.2 \mathrm{~g} \mathrm{~m}^{-3}$ for ethylacetate and xylene were 0.0175 and $0.0193 \mathrm{~m}^{3} \mathrm{~g}^{-1}$ and the corresponding $\mathrm{R} 2$ values are 0.8615 and 0.875 , respectively. These results indicated 


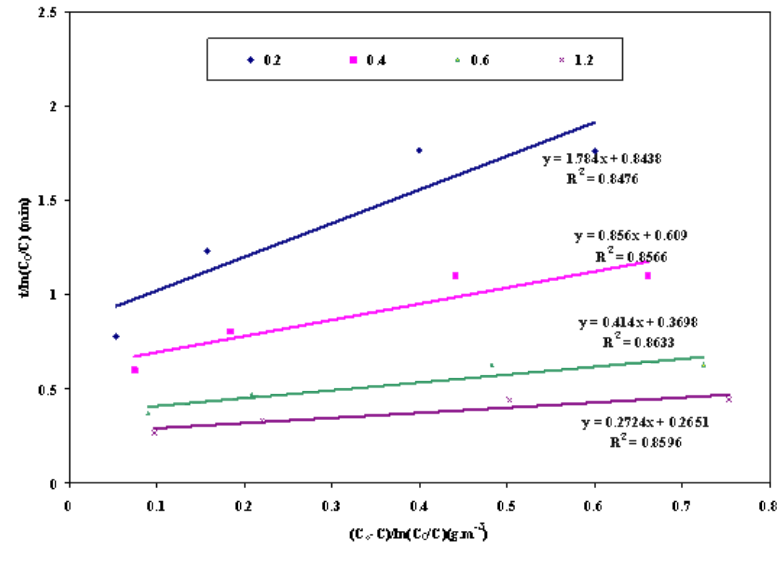

(a) ethyl acetate

Figure 4: $\left(C_{0}-C\right) / \ln \left(C_{0} / C\right)$ versus $t / \ln \left(C_{0} / C\right)$ at different EBRT

that the degree of inhibitive effect resulting from increased inlet concentration was almost the same for ethyl acetate and xylene in this concentration range.

\subsection{Biochemical reaction process}

In the maximum stationary phase, the population of viable cells was at a relatively constant value. Under the steadystate conditions, the substrate utilization rate by microbial was proposed [15]. Three situations may be encountered in a biochemical reaction system. These corresponding equations could be derived from the Michaeilis-Menten relationship to express the rates of biochemical reaction for each situation as follows:

First order kinetics:

$$
\ln \frac{C}{C_{0}}=-k_{1} t
$$

Zero-order kinetic with reaction limitation:

$$
C_{0}-C=k_{0} t
$$

Zero-order kinetic with diffusion limitation:

$$
C=C_{0}\left[1-t\left(\frac{a k_{0} D_{e}}{2 m C_{0} \delta}\right)^{1 / 2}\right]^{2}
$$

where $a$ is the interfacial area per unit volume, $D_{e}$ is the effective diffusion coefficient, $m$ is the distribution coefficient of the component, $t$ is the Empty Bed Residence Time (EBRT), $\delta$ is the biofilm thickness, and $k_{1}$ and $k_{0}$ are the rate coefficients of first-order kinetic reaction and zero-order kinetic with reaction limitation, respectively. However, for convenience of use, it is necessary to define a new parameter, $K_{d}=\left(a k_{0} D_{e} / 2 m C_{0} \delta\right)^{1 / 2}$. It can be seen that $K_{d}$ is a function of the operating conditions of the biofilter system, and $K_{d}$ is constant under steady-state conditions [16]. Therefore, Equation 6 can be rewritten as:

$$
1-\left(\frac{C}{C_{0}}\right)^{1 / 2}=K_{d} t
$$

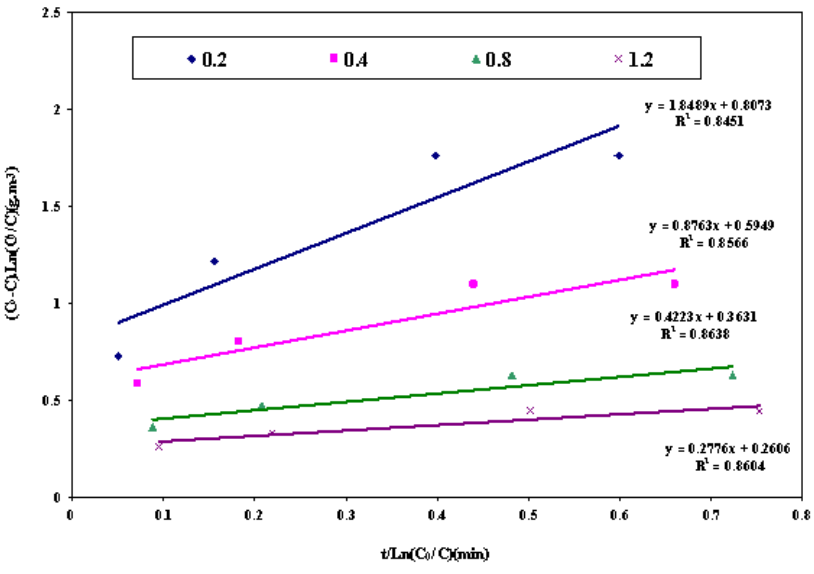

(b) xylene

Table 1: Kinetic constant and Correlation coefficient values $R^{2}$ for Michaelis-Menten equation for ethyl acetate and xylene

\begin{tabular}{l|cccc|cccc}
\hline Inlet & \multicolumn{5}{|c|}{ Xylene } & \multicolumn{4}{c}{ Ethyl acetate } \\
\cline { 2 - 9 } conc. $\left(\mathrm{g} \mathrm{m}^{-3}\right)$ & $K_{s}$ & $V_{m}$ & $R^{2}$ & $K_{g}$ & $K_{s}$ & $V_{m}$ & $R^{2}$ & $K_{g}$ \\
\hline 0.2 & 1.8489 & 0.8073 & 0.8451 & 0.0463 & 1.784 & 0.8438 & 0.8476 & 0.041 \\
0.4 & 0.8763 & 0.5949 & 0.8566 & 0.0352 & 0.856 & 0.609 & 0.8566 & 0.031 \\
0.6 & 0.4223 & 0.3631 & 0.8638 & 0.0296 & 0.414 & 0.3698 & 0.8633 & 0.025 \\
1.2 & 0.2776 & 0.2606 & 0.8606 & 0.0251 & 0.2724 & 0.2651 & 0.8596 & 0.022 \\
\hline
\end{tabular}

where $K_{d}$ is the rate coefficient of zero-order kinetic with diffusion limitation.

The plots of $C_{0}-C$ versus $t, \ln \left(C / C_{0}\right)$ versus $t$ and $1-\left(C / C_{0}\right)^{1 / 2}$ versus $t$ calculated from the data in phase III had high correlation coefficient. The rate coefficient values and correlation coefficient values $R^{2}$ are tabulated in Table 1 . It shows the $R^{2}$ values are linearized profiles developed from three kinetic models for ethyl acetate and xylene were range from 0.9249 to 0.9990 and 0.9135 to 0.9969 , respectively. Therefore, all three plots almost follow a linear relationship. In order to verify the biochemical reaction kinetic model, assume there was a plug air flow in the biofilter column and the following equation was derived from the Michaelis-Menten equation [12]:

$$
\left(C_{0}-C\right) / \ln \left(C_{0} / C\right)=V_{m}\left(t / \ln \left(C_{0} / C\right)\right)-K_{s}
$$

where $K_{s}$ is half-saturation constant and $V_{m}$ is maximum reaction rate. A plot of $\left(C_{0}-C\right) / \ln \left(C_{0} / C\right)$ versus $t / \ln \left(C_{0} / C\right)$ should correspond to a straight line, and $K_{s}$ and $V_{m}$ can be determined. The plot of $\left(C_{0}-C\right) / \ln \left(C_{0} / C\right)$ versus $t / \ln \left(C_{0} / C\right)$ for two compounds is shown Fig. 4. The calculated regression line equations for ethyl acetate and xylene were $y=$ $0.2776 x-0.2606\left(R^{2}=0.8604\right)$ and $y=0.2724 x-0.2651$ $\left(R^{2}=0.8506\right)$, respectively. Therefore, the calculated $K_{s}$ values for ethyl acetate and xylene were 1.8489 and 1.784 $\mathrm{g} \mathrm{m}^{-3}$, respectively. The calculated $V_{m}$ values for ethyl acetate and xylene were 0.8073 and $0.8438 \mathrm{gC} \mathrm{h}^{-1} \mathrm{~kg}^{-1}$ packed material, respectively. According to the MichaelisMenten concept, (I) as the substrate concentration was very low $\left(K_{s} \gg C_{0}\right)$, the reaction rate expression could be simplified to first-order kinetic; (II) as the substrate concentra- 


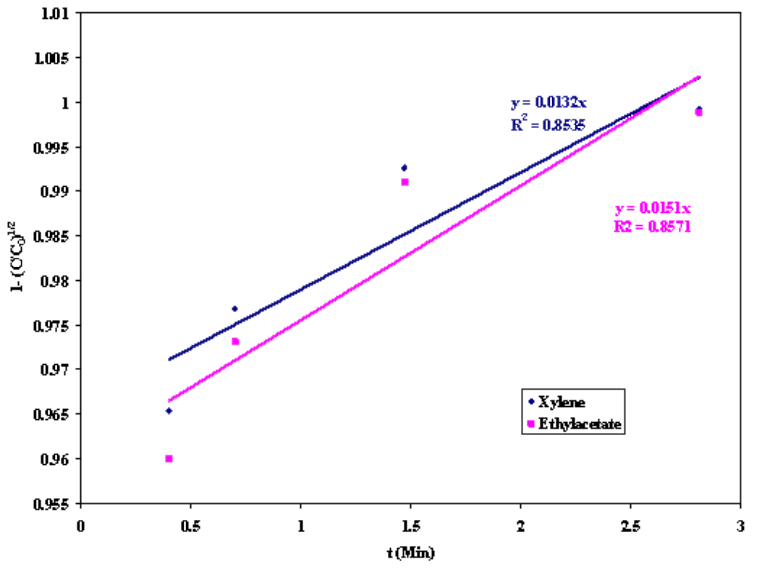

(a) at low concentrations

Figure 5: Macrokinetic determination of Michaelis-Menten kinetic constants

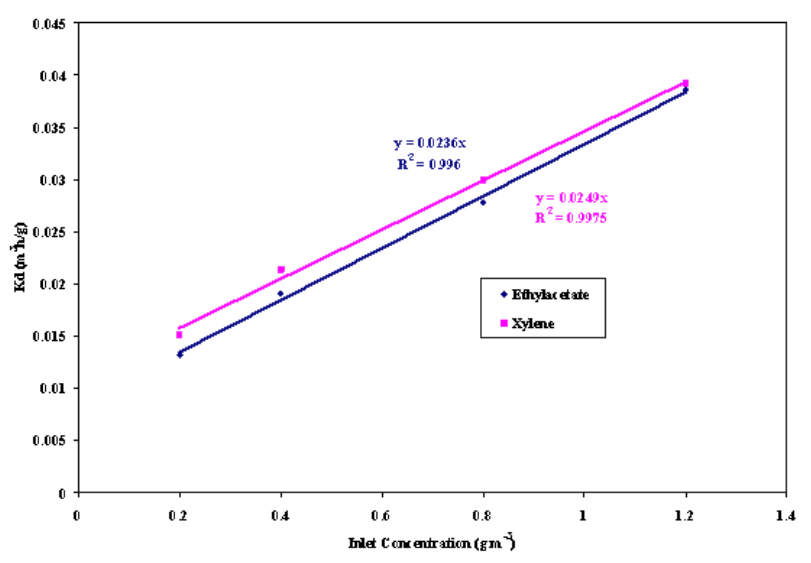

Figure 6: The variations of $K_{d}$ with inlet concentration $\left(C_{0}\right)$ for two compounds

tion was very high $\left(K_{s} \ll C_{0}\right)$, the reaction rate expression could be simplified to zero-order kinetic; (III) as the substrate concentration $C_{0}$ was comparable with $K_{s}$, the reaction rate expression could not be simplified and it was followed fractional order kinetic as Equation 7 derived by Ottengraf's diffusion limiting model [16]. The ratio values of $C_{0} / K_{s}$ for ethyl acetate and xylene were 0.108-4.38 and $0.112-4.4$, respectively. Therefore, zero-order kinetic with diffusion limitation was regarded as the most adequate biochemical reaction kinetic model because the values of $K_{s}$ and $C_{0}$ were comparable for two compounds used in this study. Thus, the $K_{d}$ value of two compounds at various inlet concentrations was calculated from Equation 7.

The variations of the $K_{d}$ values with inlet concentration $C_{0}$ for two compounds are shown in Figure 5. The $K_{d}$ value of ethyl acetate was greater than that of xylene in the inlet concentration range of $0.2-1.2 \mathrm{~g} \mathrm{~m}^{-3}$. The result indicated that the biochemical reaction rate of ethyl acetate was greater than that of xylene in this concentration range. Therefore, the compound with a low number of carbons in the main chain would be easier biodegraded by the microbial. The

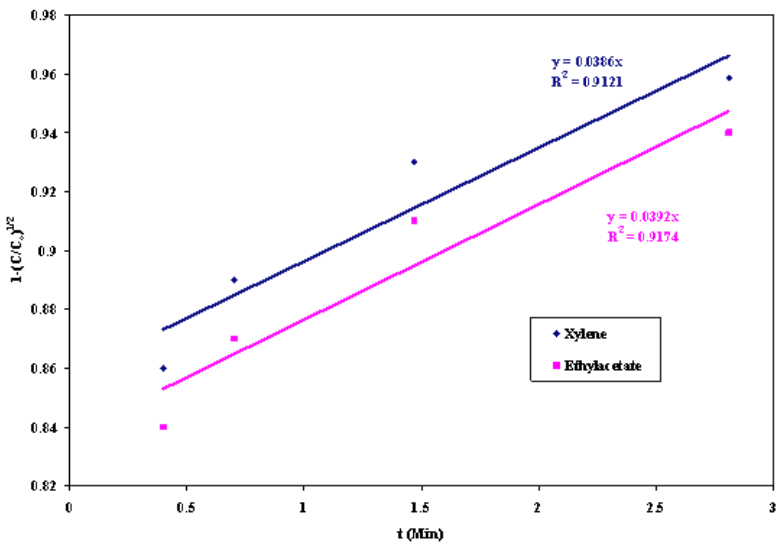

(b) at high concentrations

result was closely corresponding to the result reported that the specific degradation rate of MEK $\left(8.64 \mathrm{mmol} \mathrm{h}^{-1} \mathrm{~g}^{-1}\right.$ dry cell weight) was greater than that of MBK (2.73 mmol $\mathrm{h}^{-1} \mathrm{~g}^{-1}$ dry cell weight) [14]. The $K_{d}$ value decreased with increasing inlet concentration in the concentration range of 0.2-1.2 $\mathrm{g} \mathrm{m}^{-3}$ for both compounds. The result indicated that the inhibitive effect also predominated and the biochemical reaction rate was also inhibited at higher inlet concentration in this concentration range. The result was closely corresponding to the result reported that the biochemical reaction rate of n-butyl acetate decreased with increasing inlet concentration [10]. The slope of the linear profiles in the concentration range of $0.2-1.2 \mathrm{~g} \mathrm{~m}^{-3}$ for ethyl acetate and $\mathrm{xy}$ lene were 0.0236 and $0.0249 \mathrm{~m}^{3} \mathrm{~h} / \mathrm{g}$, respectively as shown in Figure 6 and corresponding $R 2$ values nearly 0.99 for both compounds. The result indicated that the inhibitive effect resulting from increased inlet concentration for ethyl acetate was more pronounced than that for xylene in this concentration range.

\subsection{Kinetic behavior of EAX inlet concentration along the bed depth}

This experiment was conducted to determine the local EAX concentration along the depth of the biofilter. Samples were taken from the various sampling ports at the distances $0,25,50$ and $75 \mathrm{~cm}$ from the bottom of the bed. At the time of measuring these distances from the top, plenum height of $3 \mathrm{~cm}$ and distance of outlet from the bottom of the bed have not been considered since it is assumed that there are not any conversion takes place in these sections. In order to predict the microbial kinetics behavior at EAX inlet concentration along the bed depth, an attempt was made to fit a first order kinetic mathematical model based on diffusion reaction. Contaminated profiles within the biofilter bed during phase I on day 10 (at low concentration) and during phase $\mathrm{V}$ on day 40 (at high concentration), have been shown in Figure 7. Here, it is observed that the removal of xylene is slow and slightly different from the ethylacetate. Similar trend for methyl propyl ketone, MEK, toluene and n-butyl acetate 


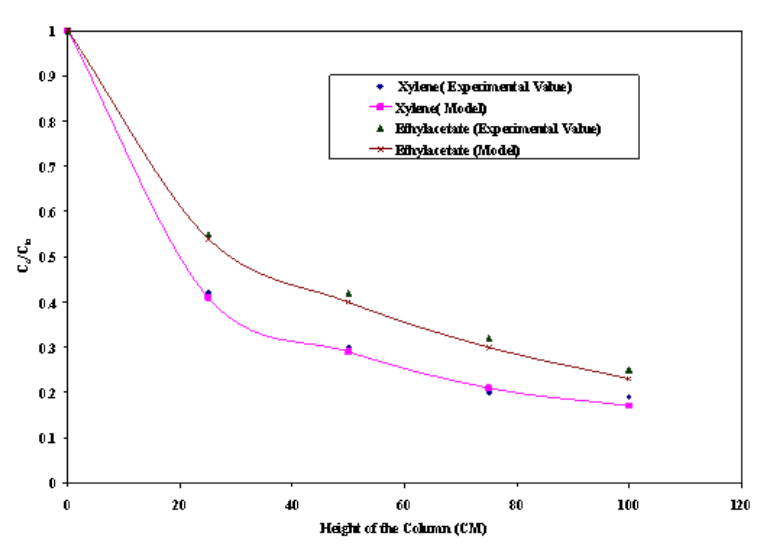

(a) at low concentrations

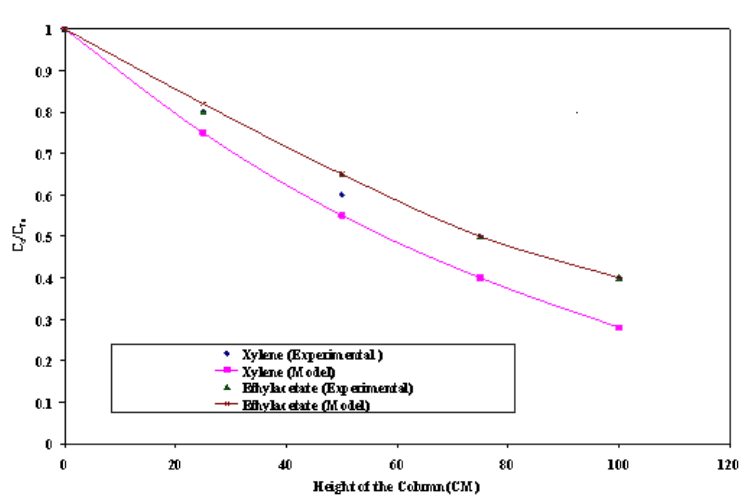

(b) at high concentrations

Figure 7: Experimental and model predicted concentration profiles of Ethylacetae and xylene along the bed depth for

mixture removal in biofilters inoculated with fungus Cladosporium sphaerospermum and packed with polyurethane, and concluded that n-butyl acetate was the most quickly degraded followed by MEK, methyl propyl ketone and then toluene[17]. Moreover, the variations of experimental concentration along the bed depth and the fitted curve (CDR model) have been presented in Figure 7(a) and Figure 7(b). Figure 7(a) shows that for a low concentration and low flow rate the model is in good agreement with the experimental values xylene and ethylacetate. At higher concentration and flow rate (Figure 7(b)), the model predicts more deviation in comparison with the experimental results. It was observed that the good agreement between the measured data and the predicted results for both concentrations (low and high) is obtained in the middle part of the biofilter. A similar trend was also observed for the mixture of isopropyl alcohol and acetone [18]. This small variation in the model results from the experimental values can be attributed to numerous factors, such as experimental error induced in the estimation of the kinetic model parameters. Overall, the discrepancy between the model and the experimental results is not significant, if one considers complexity of the model and its numerous simplifying assumptions and the experimental error in both the biofiltration performance results and the kinetic model parameters estimated [19].

\section{Conclusion}

The biochemical kinetic behaviors of ethyl acetate and xylene in a sugarcane bagasse based biofilter were investigated. The microbial growth rate $K_{g}$, biochemical reaction rate $K_{d}$ and kinetic constant $K_{s}$ were inhibited at higher inlet concentration. For the microbial growth process, the $K_{g}$ value of ethyl acetate was greater than that of xylene in the inlet concentration range of $0.2-1.2 \mathrm{~g} \mathrm{~m}^{-3}$. The degree of inhibitive effect was almost the same for ethyl acetate and xylene in this concentration range. The half-saturation constant $K_{S}$ values of ethyl acetate and xylene were1.8489 and $1.784 \mathrm{~g} \mathrm{~m}^{-3}$, respectively. The maximum reaction rate $V_{m}$ values of ethyl acetate and xylene were 0.8073 and 0.8438 $\mathrm{gC} \mathrm{h}^{-1} \mathrm{~kg}^{-1}$ packed material, respectively at a concentration of $0.2 \mathrm{~g} \mathrm{~m}^{-3}$. Zero-order kinetic with the diffusion limitation could be regarded as the most adequate biochemical reaction model. For the biochemical reaction process, the $K_{d}$ value of ethyl acetate was greater than that of xylene in the inlet concentration range of $0.2-1.2 \mathrm{~g} \mathrm{~m}^{-3}$. The inhibitive effect for ethyl acetate was more pronounced than that for xylene in this concentration range. The compound with a low number of carbons in the main chain was easier biodegraded by the microbial. In order to understand the transport phenomena and kinetic behaviors of biofilter, the kinetic constants and the EAX concentration profiles along the depth by using diffusion model were also determined. The EAX concentrations profile along the depth at low concentration and low flow rate shows that the model is in good agreement with the experimental values.

\section{References}

[1] Devinny JS, Deshusses MA and Webster TS, Biofiltration for air pollution control, Lewis Publishers, Boca Raton, Fla., 1999

[2] Carlson D and Leiser C, Soil beds for the control of sewage odors, Journal (Water Pollution Control Federation), 1966. 38(5):pp. 829840

[3] Lu C, Lin MR, Lin J and Chang K, Removal of ethylacetate vapor from waste gases by a trickle-bed air biofilter, Journal of Biotechnology, 2001. 87(2):pp. 123-130. doi : 10.1016/S0168-1656(01) 00228-0

[4] Lu C, Chang K and Hsu S, A model for treating isopropyl alcohol and acetone mixtures in a trickle-bed air biofilter, Process Biochemistry, 2004. 39(12):pp. 1849-1858. doi:10.1016/j .procbio.2003.09. 019

[5] Deshusses M, Johnson C and Leson G, Biofiltration of high loads of ethyl acetate in the presence of toluene, Journal of the air \& waste management association, 1999. 49(8):pp. 973-979

[6] Jianping W, Yu C, Xiaoqiang J and Dongyan C, Simultaneous removal of ethyl acetate and ethanol in air streams using a gas-liquid-solid three-phase flow airlift loop bioreactor, Chemical Engineering Journal, 2005. 106(2):pp. 171-175. doi:10.1016/j.cej.2004.11. 014

[7] Alvarez-Hornos FJ, Gabaldn C, Martnez-Soria V, Marzal P, Roja JMP and Izquierdo M, Long-term performance of peat biofilters treating ethyl acetate, toluene, and its mixture in air, Biotechnology and Bioengineering, 2007. 96(4):pp. 651-660. doi : 10.1002/bit. 21096 
[8] Chan WC and Hwang ID, Biochemical kinetic behaviors between n-butyl acetate and composite bead in biofilter, Applied Microbiology and Biotechnology, 2006. 73(1):pp. 226-233. doi:10.1007/ s00253-006-0471-x

[9] Chan WC and Chang LY, Kinetic behaviors between acetone and composite bead in biofilter, Applied Microbiology and Biotechnology, 2006. 72(1):pp. 190-196. doi:10.1007/s00253-005-0236-y

[10] Chan W and Lin Z, A process to prepare a synthetic filter material containing nutrients for biofiltration, Bioresource technology, 2006. 97(15):pp. 1927-1933. doi:10.1016/j . biortech.2005.08.005

[11] Reynolds TD, Unit operations and processes in environmental engineering, Brooks/Cole, Engineering Division, Monterey, Calif., 1982

[12] Valsaraj KT, Elements of environmental engineering thermodynamics and kinetics, Lewis Publishers, Boca Raton, 1995

[13] Leson G and Winer A, Biofiltration: an innovative air pollution control technology for VOC emissions, Journal of the Air \& Waste Management Association, 1991. 41(8):pp. 1045-1054

[14] Lee T, Kim J, Kim M, Ryu H and Cho K, Degradation characteristics of methyl ethyl ketone by Pseudomonas sp. KT-3 in liquid culture and biofilter, Chemosphere, 2006. 63(2):pp. 315-322. doi:10.1016/j . chemosphere.2005.07.067

[15] Ottengraf S, Biotechnology, vol. 8, Ch. Exhaust gas purification, VCH Verlagsgesellschaft, Weinheim, 1986. pp. 426-452

[16] Yang Y and Allen E, Biofiltration control of hydrogen sulfide. 2. Kinetics, biofilter performance, and maintenance, Air \& waste: journal of the Air \& Waste Management Association, 1994. 44(11):pp. 13151321

[17] Qi B, Moe WM and Kinney KA, Treatment of Paint Spray Booth OffGases in a Fungal Biofilter, Journal of Environmental Engineering, 2005. 131(2):pp. 180-189

[18] Lu C and Chang K, Biofiltration of Butyl Acetate and Xylene Mixtures Using a Trickle-Bed Air Biofilter, Engineering in Life Sciences, 2004. 4(2):pp. 131-137. doi:10.1002/elsc. 200420022

[19] Jorio H, Bibeau L, Viel G and Heitz M, Effects of gas flow rate and inlet concentration on xylene vapors biofiltration performance, Chemical Engineering Journal, 2000. 76(3):pp. 209-221. doi:10.1016/ S1385-8947 (99) 00160-6 